\title{
LAS DETERMINACIONES POLÍTICAS EN MATERIA DE DERECHOS HUMANOS. CONSIDERACIONES DESDE LA ÉTICA WEBERIANA Y DESDE LA FUERZA TRASCENDENTAL HEGELIANA
}

\section{POLITICAL DETERMINATIONS IN THE FIELD OF HUMAN RIGHTS. CONSIDERATIONS FROM THE WEBERIAN ETHICS AND FROM THE HEGELIAN TRANSCENDENTAL FORCE}

\author{
Jesús Victor Alfredo Contreras Ugarte ${ }^{1}$ \\ Doctor Sobresaliente Cum Laude en Derechos Humanos \\ Instituto de Derechos Humanos Complutense \\ Universidad Complutense de Madrid \\ jesuco_amag@yahoo.es \\ España
}

\section{SUMARIO}

- Disimilitud entre convicción y obligación

- Convicción y responsabilidad en Max Weber

- La fuerza trascendental hegeliana frente a la realidad

- Conciencia y convicción en las determinaciones políticas

- Percepciones finales

\section{RESUMEN}

Pareciera que las determinaciones políticas se tuvieran que tomar siempre desde un enfoque frívolo de cálculo y conveniencia. Hablar de anteponer el interés de los valores y los derechos humanos a cualquier otra situación que, en términos políticos, pueda resultar más cómoda y manejable, hay quien cree que es lo correcto por razones de practicidad y de mejor protección de los intereses particulares de una nación y de sus ciudadanos. En este artículo sostengo que esto es un error y que el respeto y atención a los valores y derechos humanos de todos y, la consciencia y convicción de ellos y de su superioridad, son de capital importancia en el ejercicio de las decisiones políticas.
Reflexiono desde la ética de Max Weber y desde la idea de la fuerza trascendental hegeliana.

\begin{abstract}
It seems that the political determinations always had to be taken from a frivolous approach of calculation and convenience. To speak of putting the interest of values and human rights before any other situation that, in political terms, may be more comfortable and manageable, there are those who believe that it is the right thing for reasons of practicality and better protection of the particular interests of a nation and its citizens. In this article I argue that this is a mistake and that respect and attention to the values and human rights of all and their awareness and conviction and their superiority are of paramount importance in the exercise of political decisions. I reflect from the ethics of Max Weber and from the idea of Hegelian transcendental force.
\end{abstract}

\section{PALABRAS CLAVE}

Determinaciones políticas, responsabilidad, fuerza trascendental, conciencia y convicción, Weber, Hegel.

1 Abogado-Licenciado en Derecho: Facultad de Derecho - Universidad de San Martín de Porres; Máster en Derechos Fundamentales, Especialista en Educación para la Ciudadanía y los Derechos Humanos, Máster en Estudios Avanzados en Derechos Humanos, Doctor Sobresaliente Cum Laude en Estudios Avanzados en Derechos Humanos: Instituto de Derechos Humanos "Bartolomé de las Casas" - Universidad Carlos III de Madrid; Especialista con Matrícula de Honor en Derechos Humanos: Instituto de Derechos Humanos de la Facultad de Derecho de la Universidad Complutense de Madrid. Investigador y colaborador académico de Filosofia del Derecho y Derechos Humanos en la Facultad de Derecho de la Universidad Complutense de Madrid. 


\section{KEYWORDS}

Political determinations, responsibility, transcendental force, conscience and conviction, Weber, Hegel.

\section{DISIMILITUD ENTRE CONVICCIÓN Y OBLIGACIÓN}

Convencido estoy de la necesidad de que toda persona humana deba contar con una conciencia y convicción de sus valores y derechos humanos. Esto es trascendental para lograr una verdadera paz social y un sostenible desarrollo humano. Es clara la superioridad de la convicción como mejor instrumento para lograr una real eficiencia en el respeto hacia los derechos humanos, y más allá de la formal obligación legal que obligue a respetarlos. En este sentido, empezaré haciendo una diferenciación entre lo que debemos entender por obligación frente a lo que es la convicción.

La obligación es todo aquello que hacemos o no hacemos, obligados -valga la redundanciapor algo o por alguien. No importa ya si creemos que eso que hacemos o no hacemos es correcto o incorrecto, o si es lo que verdaderamente queremos hacer. Cumplimos con ese hacer, o con ese no hacer, porque existe una consecuencia que se produce o que se podría producir si yo no cumplo con aquello a lo que se me obliga. Esto significa que en la obligación existe una sanción, algún medio coercitivo o alguna consecuencia negativa que quiero evitar $\mathrm{y}$, la forma de evitarlo es cumpliendo o haciendo algo que impida que ese hecho negativo surta sus efectos, sin importar que esto vaya o no en contra de mis convicciones y creencias. En el escenario de la obligación, lo que interesa es evitar el perjuicio particular e inmediato, no la trascendencia general o el efecto final que se produce en uno mismo y en el resto de la sociedad.

Notemos que es en el marco de la obligación en el que se mueve, principalmente, el Derecho $y$ con el que se sustenta la mayor parte de la producción de sus normas legales: el de obligar formal y legalmente para que los sujetos eviten una sanción represora o castigadora o algún otro perjuicio determinado. En cambio, la convicción se mueve en otro marco de entendimiento y, a mi juicio, en un marco muy superior en cuanto a consecución de eficiencia de fines se trata.

La convicción implica que yo hago o dejo de hacer algo, porque creo que con ello hago lo correcto o, simplemente, porque quiero hacerlo o dejar de hacerlo, y no tengo en cuenta, para determinarlo, la consecuencia que se provoque, me sea esta perjudicial o no. Este es un estado de convencimiento espontáneo y profundo de los sujetos que es más eficiente $\mathrm{y}$ sólido para mover, en un sentido $\mathrm{u}$ en otro, las decisiones y determinaciones de los individuos ya que, haya o no consecuencias represoras o negativas que intenten obligarnos a algo, siempre se actuará guiados por las convicciones propias, es decir, por convencimiento. La convicción no necesita verse obligada o amenazada con alguna sanción o consecuencia dañina para ejercerse o cumplirse con ella. Este es el nivel que se alcanza con una conciencia crítica y activa del valor humano. Esto es lo que nos conduce a una verdadera conciencia de libertad. Mi certeza de la mayor eficiencia del sentimiento de convicción, por encima del sentimiento de obligación (que solo busca evitar una sanción o un perjuicio), la puedo sustentar muy bien en las palabras del filósofo italiano Rodolfo Mondolfo (1962), quien afirma que:

la necesidad de la propia expansión es 'tendencia viva, verdadera y pura, que nada desmiente nunca en la más profunda interioridad', a la alegría de hacer felices a los demás, que es la más dulce de cuantas puedan existir, a condición de que sea 'libre y voluntaria'. Cuando no interviene el peso de la exigencia ajena, de la extrema obligación coactiva, a la que nuestra espontaneidad se rebela, 'la fuerza de un alma expansiva me identifica con mi semejante'. (Página 43 - 44)

Por otro lado, no se me pasa por alto que también debemos de instaurar un cierto límite al instrumento eficiente de la convicción, sobre todo en los actos de gobierno y en los actos del Derecho pues en la práctica social y política, muchas veces, la convicción debe ponderarse con la responsabilidad. Esto lo entenderemos mejor si nos situamos en la esclarecedora sociología weberiana y a su clásica distinción entre la ética de la convicción y la ética de la responsabilidad. 
Political determinations in the field of human rights. Considerations from the

weberian ethics and from the hegelian transcendental force

\section{CONVICCIÓN Y RESPONSABILIDAD EN MAX WEBER}

Empiezo aclarando que no pretendo decir que quien actúa por convicción es necesariamente irresponsable o que quien actúe por responsabilidad carece de convicción. Una cosa no excluye a la otra, necesariamente. Lo que sí voy a advertir es la diferencia que existe entre estas dos formas de actuar.

Quien actúa guiado únicamente por la ética de la convicción actúa según lo que le "ordena" ella y sin mayor miramiento hacia los fines finales que persigue conseguir; actúa por lo que considera acorde a sus convicciones, sin importar lo que ello origine. En cambio, quien actúa guiado por la ética de la responsabilidad sí actúa teniendo en cuenta las consecuencias previsibles que podrían producirse con su actuar; como apunta Weber (2007), por muy convincentes que resulten los argumentos explicados a un sindicalista que le adviertan de consecuencias negativas, como incrementar la eventualidad de la reacción, acrecentar la subyugación de su clase y obstaculizar o complicar su ascenso: “(...) si ese sindicalista está firme en su ética de la convicción, (...) no lograrán hacerle mella.”(Página 165).

Luego, quien actúa por la ética de la convicción, si con su actuar provoca perjuicios, este no se considerará responsable de dichos perjuicios; por el contrario, responsabilizará de ello al mundo, a la torpeza de los otros o la voluntad de una fuerza supuestamente invencible; la única responsabilidad que estará dispuesto a asumir es la de perder la pasión convencida de su convicción, y sus acciones estarán dirigidas a mantener dicha pasión, las que únicamente deben y pueden tener un valor ejemplar dentro del marco de sus convicciones. Sin embargo, quien guía sus actos de acuerdo a la ética de la responsabilidad, atenderá a todas las imperfecciones posibles de sus actos y asumirá que esos perjuicios se deben a su acción. Sobre esto, Max Weber (2007) terminará concluyendo que la ética de la convicción no es la más conveniente para conducir el accionar político. Para Weber (2007), es la ética de la responsabilidad la que le corresponderá al actuar político. Y es que en la ética de convicción no se añade remedio alguno al asunto sobre la motivación de las vías y mecanismos que deben ser usados en la política; el razonamiento que sigue la ética de la convicción es de talante absoluto ya que no acepta otra posibilidad más que la que guía la convicción misma. En este sentido apunta Joaquín Abellán (2004) que:

(...) la aplicación de la ética de las convicciones a la política significa convertir la lucha política en una lucha de carácter religioso, que ignora la naturaleza fundamentalmente diabólica del poder, es decir, que ignora que ni los mejores ideales ni las mejores intenciones son capaces de eliminar la naturaleza trágica de la política. La utilización de la política para la realización de objetivos absolutos sin dar entrada de manera determinante a las consecuencias de esa realización conduce finalmente a un descrédito de los propios ideales. (Página 197-198)

En la ética weberiana se sostiene que no se pueden lograr objetivos correctos sin utilizar medios que a veces son moralmente dudosos o peligrosos $\mathrm{y}$, además, pueden provocar consecuencias moralmente incorrectas; no existe tampoco ética que determine "(...) cuándo y en qué medida quedan 'santificados' por el fin moralmente bueno los medios y las consecuencias laterales moralmente peligrosos.”(Weber 2007, página 166)

Por otro lado, puedo reconocer que, en cierta medida, la historia nos ha mostrado que quienes se guían únicamente por la ética de la convicción terminan olvidando su conciencia de la responsabilidad. Por su parte, también es cierto que las situaciones del mundo no son tan inflexibles, inconmovibles y estructuradas como para creer que siempre de todo lo bueno va a brotar el bien y de todo lo malo, el mal. La vida humana no tiene esos niveles de racionalidad lógica y exacta, y la política no es la excepción. No obstante, el ser humano que ejerce el poder no tiene que estar siempre supeditándose a prever, calculada y estratégicamente, si va a lograr o no resultados socialmente óptimos y correctos en sus acciones, ni tampoco limitarse a una única forma de decidir, sea sujetándose a la ética de la responsabilidad o no. El mismo Weber (2007) parece entenderlo así, pues pese a que opina que la ética de la responsabilidad es la que debe conducir a la política; empero, reconoce que la ética de la convicción tiene un componente de ilusión y de firmeza hacia la entrega del objetivo en el que se cree y el que se quiere alcanzar. Si bien es mejor ejercer las acciones políticas con responsabilidad, 
para Weber (2007), estas deben encontrar su límite cuando el político se sienta obligado a detenerse por sus convicciones.

Las convicciones las llevamos en el interior de nuestro ser y son la muestra más clara y pura de nuestra propia vida activa; son la evidencia de que nuestro ser no está muerto interiormente. Por ello, el auténtico político y, en general, cualquier persona que quiera ser auténtica y correcta en su accionar, debe obrar con el sentimiento de estar haciéndolo por ese compromiso ideal en el que cree, por su convicción de que lo que hace lo hace siguiendo los requerimientos del interior de su ser. La convicción es una fuerza que nos permite desenvolvernos con entereza en la realidad, sin derrumbarnos interiormente, frente a las caídas y avatares que se nos presenten. Así pues, puedo asegurar que la ética de la responsabilidad y la ética de la convicción, en la vida en general, resultan perfectamente complementarias para nuestra mejor existencia. A este respecto, Weber (2007), refiriéndose al político, dice que:

Es infinitamente conmovedora la actitud de un hombre maduro (de pocos o muchos años, que eso no importa), que siente realmente y con toda su alma esta responsabilidad por las consecuencias y actúa conforme a una ética de responsabilidad, y que al llegar a un cierto momento dice: 'No puedo hacer otra cosa, aquí me detengo'. Esto sí es algo auténticamente humano y esto sí cala hondo. Esta situación puede, en efecto, presentársenos en cualquier momento a cualquiera de nosotros que no esté muerto interiormente. Desde este punto de vista la ética de la responsabilidad y la ética de la convicción no son términos absolutamente opuestos, sino elementos complementarios que han de concurrir para formar al hombre auténtico. (Página 77)

Quede claro pues, que pienso que la ética de la convicción no descarta a la ética de la responsabilidad; más bien, creo que ambas, pese a ser opuestas en la consideración de sus consecuencias, no dejan de ser complementarias y necesarias, sobre todo para el ejercicio del poder político de quienes nos representan y, más aún, en materia de derechos humanos. Un poder político responsable tiene que atender y respetar a los valores y derechos humanos superiores, los que no pueden estar sujetos a condicionamientos; pero, a la vez, estos derechos y valores, tienen que estar dispuestos a ser limitados, excepcionalmente, cuando se conjeturen consecuencias de mucha gravedad. La ética de la convicción por sí sola no es perfecta, al igual que la ética de la responsabilidad. Ambas se necesitan para surtir efectos eficientes sobre la humanidad. $\mathrm{Y}$ esto es así porque en la realidad humana la perfección es inalcanzable; la perfección humana en sí es imperfecta porque nuestra naturaleza también lo es. Con lo cual lo que se busca en la sociedad, dentro de su imperfección natural, es que sea lo más justa posible; es decir, que en su imperfección no se alcancen niveles delicados, de injusticia y de discriminación que provoquen una situación crítica en la que los mismos seres humanos desvirtúen y desmerezcan su propio valor, sobredimensionando y prefiriendo otros valores de menor o de ninguna envergadura humana.

Entonces, sostengo que la convicción, dentro de la conciencia de los valores y derechos humanos, es indispensable para lograr la eficiencia práctica de los mismos dentro de la humanidad y es, precisamente esa convicción, la que hace que las decisiones políticas se ejerzan también con responsabilidad y con preocupación por las consecuencias que se puedan ocasionar.

\section{LA FUERZA TRASCENDENTAL HEGELIANA FRENTE A LA REALIDAD}

Para Hegel la historia es un enorme proceso de liberación del espíritu universal que supone el avance en el logro de la autoconsciencia. La historia, para Hegel (1968), es exhibición de los momentos de la razón, de su conciencia de sí y de su libertad, es la explicación y la realización del espíritu universal. Según Hegel (1968), existe un objetivo hacia donde se dirige la historia del mundo; este objetivo es la conciencia universal de libertad. Esta conciencia universal de libertad, se basa en el principio de la libertad del ser humano en cuanto ser humano que es y es aquí, donde la conciencia universal de libertad encuentra su más alto grado de superioridad. Este principio, desde mi punto de vista, y a diferencia de Hegel (1968), contiene en sí mismo a toda la humanidad. Para Hegel (1968), recordemos, hay una fuerza universal e inmanente que mueve al mundo dialécticamente, y esta fuerza no es otra que la razón. En la razón es donde el ser humano y sus intereses particularistas, guardan un nivel secundario o de menor 
relevancia que esa fuerza universal, superior y trascendente, que es la que decide las cosas en el mundo y en la realidad. Una suerte de providencia que desciende del cielo a la tierra.

Particularmente, no comparto la idea de Hegel (1968) de someter el progreso de la humanidad a una fuerza trascendental que lo decida todo; por buena o mala que sea esta fuerza; pienso que esto dejaría al ser humano convertido en algo que no puedo aceptar. El ser humano no es una marioneta ni un robot al que una fuerza trascendental lo decida o programe, determinante e ineludiblemente, en un sentido o en otro; este es un error de entendimiento en el que se puede caer si se cree que el ser humano no es capaz de trascender y de determinar su acaecer; el ser humano es más bien autónomo y tiene el libre albedrío de decidirse; el ser humano no es un autómata al que una fuerza trascendental y determinante le imprima la resolución de su vida. El ser humano educado y formado en la conciencia y en la convicción de sus valores y derechos humanos y ciudadanos es un ser humano poderoso, capaz de cambiar el mundo en el sentido que determine. En este sentido, es el ser humano quien también dirige las decisiones políticas, y estas deben dirigirse a lograr un mundo estable, solidario, inclusivo $\mathrm{y}$ justo. No existe una fuerza trascendental que determine realidades infranqueables e imposibles de transformar.

Lo de Hegel (1968) hay que tomarlo como la descripción de una patología social en la que se puede caer y en la que, de hecho, demasiada humanidad ya ha caído; pero, de ningún modo es la regla a la que todos estemos determinados; aunque, podríamos decir que, en cierta forma, esa fuerza trascendental y determinante hegeliana se parecería, o se podría equiparar, a los poderes económicos y de mercado imperantes en la actualidad que parecen decidir lo que sucede en la realidad. No obstante, esto, en todo caso, es un problema; no es lo inevitablemente correcto, trascendental o natural que haya que aceptar sí o sí. Tengo el firme convencimiento de la fuerza y capacidad que los seres humanos podemos alcanzar para cambiar el mundo hacia una eficiencia real de armonía y justicia. El antídoto para la patología que se desprende de la dialéctica trascendental hegeliana, es, definitivamente, la educación, la capacidad crítica y la cultura reflexiva y permanente en valores y derechos humanos, y de la que no debieran librarse ningún representante político.
Por lo tanto, hay que rechazar la idea de que el progreso de la realidad dependa, inevitable y necesariamente, de una fuerza trascendental que es la que decide la historia y la realidad de la humanidad; no es lo correcto ni lo humanamente natural y según nuestras capacidades. No podemos aceptar que por nacer en un determinado país o en una determinada realidad social nuestro destino esté ya decidido y determinado inexorablemente. Nuestros representantes políticos deben tener una conciencia de libertad y de progreso de la humanidad entendida como conjunto trascendental y vinculado, y las decisiones deben tener en cuenta esta responsabilidad que nos es insoslayable a todos en general y, sobre todo, a quienes nos gobiernan, en particular.

Lo cierto es que Hegel (1968) construye así su dialéctica porque es él que se encuentra desencantado de la fuerza activa y consciente del ser humano. Hegel (1968) ya no confía o no cree que el ser humano tenga la suficiente capacidad para hacer progresar al mundo desde su propia convicción, ni tampoco cree que sea capaz de alcanzar el entendimiento de su propio valor humano desde sí mismo $\mathrm{y}$, es por ello, que Hegel (1968) introduce en su filosofía la necesidad de una fuerza trascendental y determinante -pero que termina siendo abstracta- que permita al ser humano entenderse a sí mismo y entender el fin que cumple al ser parte de una misma totalidad; sin embargo, todo este entender lo determinaría y se lograría gracias a esa fuerza trascendental hegeliana. Es decir, el entenderse a sí mismo y el entender los fines para los que existimos nos lo determinaría una fuerza extraña a nuestro propio ser y extraña a nuestras propias capacidades pues en los conceptos hegelianos no tendríamos la capacidad de determinarnos en la realidad ni de entendernos por y desde nosotros mismos. En este mismo sentido, Jacques D’Hondt (1971) escribirá:

Hegel se resignaría ante la impotencia del pensamiento humano, condenado a aceptar las cosas e incapaz para corregirlas o reformarlas. Vería en la conciencia nada más que un simple epifenómeno, y esta derrota se manifestaría acompañada de un sentimiento melancólico, de esa tristeza amarga que se apodera del espíritu al fin de una jornada carente de acción, de una vida sin eficacia. (Página 127). 
En este extremo, no puedo estar de acuerdo con Hegel (1976) y a diferencia de él sostengo que la historia de la humanidad es un continuo desarrollo que tiene como resultado el progreso pero que su centro propulsor y determinante lo constituye la actividad del ser humano y no una fuerza trascendental, abstracta, extraña y condicionante. Esa actividad del ser humano resulta más relevante y decisiva en el ejercicio y capacidad de las determinaciones políticas que toman los que nos gobiernan. Hegel (1976) quita de la centralidad de la historia y de la realidad al ser humano, cuando lo cierto es precisamente todo lo contrario ya que al ser humano es activamente el centro propulsor y determinante de esa realidad. Son los individuos los que toman las decisiones, son los que tienen la calidad de protagonistas de la historia y son los que echan a andar la creación, el desarrollo y el progreso de la realidad social, para bien o para mal, con acierto o no.

\section{CONCIENCIA Y CONVICCIÓN EN LAS DETERMINACIONES POLÍTICAS}

Luego de lo anterior, queda claro que mi consideración es que el ser humano es quien crea sus condiciones de vida desde su voluntad, desde sus capacidades propias y sin determinaciones o fuerzas trascendentales que lo decidan. Luego, estas condiciones de vida creadas actuarán sobre su creador -es decir, sobre el mismo ser humano que las creo- $\mathrm{y}$, es este creador, quien debe superar las condiciones de vida creadas por él mismo. Siendo así, la realidad ocasionada por la acción del ser humano es la condición del desarrollo o progreso de las acciones futuras, las que son sus consecuencias. Por tanto, se trata de una autotransformación continua de la sociedad. Toda la historia está presente en nuestra humanidad pues es de ella desde donde emana. La realidad entonces, es aquella a la que el ser humano le da forma. Si la realidad no es producto de la acción voluntaria del ser humano, no es parte de la realidad o historia humana porque la realidad humana, para ser tal, tiene que ser propulsada por la intervención del ser humano. Se transita, recíproca y constantemente, de lo social al individuo y de este a lo social; se trata de un tránsito opuesto, desde la totalidad colectiva de la sociedad a la particularidad individual o colectiva de los seres humanos. Más o menos en este sentido, podemos encontrar lo que propone el filósofo humanista italiano
Rodolfo Mondolfo (1961), ya que, según él, en la oposición dialéctica entre individuo y sociedad, nos desarrollamos, progresamos $\mathrm{y}$ reconstruimos continua e incesantemente $\mathrm{y}$, con ello, desarrollamos, progresamos y reconstruimos a la humanidad. Es que la humanidad vive de la vida y de las relaciones de sus individuos. Y por consiguiente, la humanidad también vive de las decisiones de sus individuos, incluidas las políticas. Con sus decisiones, los individuos hacen la realidad y la deciden en su presente y en su futuro.

El ser humano no es un sujeto pasivo per se -ni debería aceptar serlo- donde la historia le inscriba o le determine contenidos y facultades. Los seres humanos no podemos ser reducidos a simples sujetos pasivos de la historia y de la naturaleza, o a simples sujetos dormitados, inconscientes y distraídos hacia todo lo que pasa a nuestro alrededor y en toda la realidad humana. El mundo y los seres humanos constituyen el mundo social, y este se conformó mediante la aglomeración de fragmentos, componentes y sucesos que nosotros llamamos historia; por ello, el mundo social, y así lo opina Pierre Bourdieu (2001): (...) no puede ser reducido a una concatenación de equilibrios instantáneos y mecánicos en los que los hombres juegan el papel de partículas intercambiables (Página 131).

Existe pues la necesidad de que nos entendamos cada uno, interior e individualmente, para luego poder entender que pertenecemos al resto de la humanidad, somos seres vinculados, indefectiblemente, a los demás y a todo lo demás. Una de las características de la dignidad humana es la sociabilidad y esto atendiendo a que el ser humano, en su desarrollo y desenvolvimiento de vida, es un ser sociable por naturaleza y necesidad; nuestra personalidad no se desarrolla bien en soledad y aislada de los demás. Somos seres conectados con todo y todos los demás. La sociabilidad:

Supone el reconocimiento del otro como tal otro y el de la imposibilidad de alcanzar en solitario el desarrollo de la dignidad (...) radical necesidad de la convivencia. (...) Es la dignidad que deriva de nuestra condición relacional. (Peces Barba 2005, página 66-67)

Toda esta ineludible conexión, nos impone la necesidad de contar con una conciencia y convicción activa sobre el valor de nuestra 
humanidad en las decisiones que tomamos, $\mathrm{y}$ en las que toman nuestros representantes políticos. Esta es la conciencia de que tenemos la necesidad de entender nuestra existencia y de entendernos como seres trascendentes con capacidad de decidir y determinar nuestro destino, sin obviar que además de seres trascendentes somos seres vinculados a los demás en tanto pertenecemos a una misma y única humanidad. El valor de la verdad real y vinculante de nuestra existencia, el amor propio de cada uno de nosotros y el respeto hacia nuestra humanidad se establecen luchando contra los errores y contra los fraudes de verdad que pretenden o dicen ser "lo todo valioso y verdadero". A partir la conciencia que se expresa en la lucha interior contra el mal, nacerá la conciencia laboriosa que busca el bien para la humanidad. El estímulo contemplativo de considerar o tener presente a los demás parte de la unidad del propio espíritu con la totalidad infinita del ser; esto no es negación ni disolución de la personalidad y de la propia autoconciencia que nos lleve al delirio embelesado de lo que significa nuestra existencia. La conciencia y convicción de que nuestra existencia se encuentra indefectiblemente vinculada, constituye más bien el aserto más cierto y rebosante de nuestro ser que completa nuestra propia personalidad interior y espiritual en su potencia expansiva. En este sentido, autores como Rodolfo Mondolfo (1962) dirán que:

(...) el amor de sí en su misma afirmación se expande 'en un cierto impulso del corazón hacia goces sentidos como necesidad (...); el 'vacío inexplicable sentido en sí mismo' se colma de la ternura del 'placer delicioso y puro de la humanidad' y del abandono extático en la infinitud del todo. El amor de sí se convierte en impulso de amor hacia el sistema universal de las cosas, en inspiración moral (...). Recibiendo de la intimidad de la conciencia su contenido y su valor, se eleva a sentimiento de la dignidad de la naturaleza humana y de la armonía o identidad entre los fines de la personalidad y el sistema universal. (Página 44-45)

Seguro estoy, que la verdadera libertad es algo que se conquista, pero esta libertad verdadera únicamente se alcanza con una actitud activa, consciente y vigilante desde nuestro interior; interioridad de nuestro espíritu que debe entender el verdadero valor humano: "No hay que rendirse al desaliento. (...) Entro lo que 'es' y lo que 'debería' o 'podría ser', entre los sueños y la realidad, sólo hay un puente posible: la acción."(Falcón y Tella 2006, página 110). Esto solo se logra desde la convicción, forjada a partir del ejercicio consciente de la capacidad crítica y reflexiva sobre todo lo que hay. La vida en sociedad, el mundo social y sus componentes educativos, deben proyectarse a conseguir en sus ciudadanos el sentimiento y la convicción de ser individuos verdaderamente libres, poseedores de un pensamiento propio y de una personalidad capaz, crítica y activa. Esto es lo único capaz de generar una conciencia sólida en cada uno de los integrantes de nuestras sociedades; es con ello que se gesta una conciencia pública que sabrá exigir a los poderes públicos el respeto hacia sus valores $\mathrm{y}$ derechos, para que estos sean eficaces $\mathrm{y}$ antes bien, y, sobre todo, eficientes. Esta es la forma de sostener y mantener una sociedad justa, libre de poderes sin escrúpulos que pretendan dominar todo y a todos, libre de élites privilegiadas que hacen lo necesario para favorecer sus intereses particularistas en detrimento de los demás que le sean ajenos a ellos y allegados de privilegio. La conciencia y convicción de nuestras capacidades, de nuestros derechos y vinculaciones, nos permite ejercer la resistencia contra quienes pretendan negar nuestra trascendencia y posibilidad de determinación; nos permite tener conciencia pública de que somos capaces de ejercer fuerza sobre las decisiones políticas para que nuestros derechos se respeten y se mantengan. Solo con una conciencia convencida de su valor y sólidamente sensible a su ser, forjada constantemente, se logrará alcanzar el vigor y el espíritu necesario para lograr el respeto hacia nuestra libertad de pensamiento, de expresión, de conciencia autónoma y de libertad de crítica:

Es necesario, (...) difundir y mantener viva la conciencia del peligro inherente a la mentalidad del hombre masa, que renuncia a la autonomía espiritual; es necesario hacer sentir que la libertad no es una pertenencia que, conquistada una vez, se mantiene en pie por su propia fuerza; sino que es una conquista incesante, que es necesario renovar diariamente, hora a hora, con la tensión vigilante de cada uno y de todos. (Mondolfo 1971, página 67) 
Hay que tener en cuenta, en principio, que por nuestro valor humano y universal en la sociedad, podemos y debemos exigir y exigirnos nuestros derechos y el respeto de los mismos, pero esto conlleva la necesidad de tener la conciencia del valor superior de nuestros derechos humanos; en este sentido, el tener esta conciencia, es un deber humano, universal, cívico y democrático, para todos sin excepción, pero, sobre todo, para los que toman las decisiones políticas y los que dirigen las sociedades:

Si individuos libres e iguales pactan para superar los inconvenientes del Estado de naturaleza, quien afecta los fundamentos de la sociedad civil, con todo el prejuicio para los bienes y libertad de sus miembros, entra en estado de guerra contra estos, quienes tienen habilitado su derecho a la resistencia. La reacción del pueblo puede ser terrible y el gobernante o magistrado tentado por el ejercicio del poder arbitrario debe saberlo perfectamente. (Vargas 2018, página 201)

$\mathrm{Y}$ es que, en la colectividad cívica de una sociedad, a todo derecho le corresponde un necesario deber. La conciencia de poder exigir un determinado derecho y el deber de respetarlo, no pueden ser eficientes si son ajenos a la conciencia de saber el valor humano que se contiene en dicho derecho, y por igual para todos. La conciencia de lo primero no puede estar desconectada de la conciencia de lo segundo.

Pues bien, ahora voy a fijarme en el Derecho y en las decisiones políticas en relación con lo que se espera de una sociedad justa. Parto de la idea de que el Derecho se origina en relación y paralelismo con el concepto de persona -que es el sujeto de derecho-; es decir, de la idea de igualdad jurídica al interior de la sociedad civil: “( ....) en cuanto personas en general todos somos iguales (...)" (Wences 1998, página 133). El ser humano vale por el hecho de serlo.

Luego, el fin del Derecho, y de toda decisión política en derechos humanos, es lograr una sociedad justa, democrática y decente $\mathrm{y}$, para ello, se tiene que centrar, necesaria y prioritariamente, en proporcionar el marco y medios necesarios para que los ciudadanos alcancen el pleno desarrollo de su personalidad y de su dignidad humana. El papel que desarrolla el Derecho en nuestras vidas es crucial para el orden social, entendido este como el medio capaz de organizar a la colectividad de tal forma que se eviten los abusos y oportunismos de unos sobre otros. En este sentido debemos tener en cuenta las palabras del ilustre autor español, Catedrático y Filósofo del Derecho, José Iturmendi Morales (1983):

(...) el Derecho se aplica directamente sobre el entretejido de la convivencia social, en que los hechos de la existencia colectiva se integran en los supuestos de la norma jurídica. La realidad jurídica resulta ser por ello más profunda y compleja (...). (Página 591)

Sin embargo, esto conlleva la necesaria correspondencia con el deber de contar activamente con la conciencia sobre el valor verdadero de los derechos humanos que son superiores y prioritarios a cualquier interés que los vulnere y contravenga. Debe contarse intensa y activamente con la conciencia y convicción del valor humano, pues es ello lo que nos permitirá alcanzar el bienestar particular y social para cada una de nuestras sociedades haciéndolas más justas para todos. De esto depende la realización eficiente del fin mismo del Derecho, pues el conocimiento y el cumplimiento activo de esta conciencia y convicción de la superioridad del valor humano, coinciden con la eficiencia de lo buscado por el Derecho y por las decisiones políticas justas.

El desarrollo universal de la personalidad humana no se logra sin poner en actividad nuestras energías y conocimientos conscientes: "Pues si, como es indudable, la felicidad resulta sobre todo de una inteligente actividad (...)" (Comte 1985, página 164). Esto me lleva a afirmar que, en busca de una real eficiencia, debemos también tener claro que la ausencia de respeto y de conciencia hacia nuestro valor humano, tanto de nosotros mismos como de los demás, supone, inevitablemente, un problema para la libertad, para la autenticidad y dignidad de nuestra propia humanidad y la de los demás. Si no se tiene conciencia de este problema como tal, el vigor y el impulso necesarios para el ejercicio activo de nuestras energías conscientes, simplemente pierden fuerza y protagonismo. En ese momento corremos el riesgo de dejarnos llevar por todo lo que hay, transformándonos en meros sujetos sujetados por el sistema, envueltos en la inercia y la desidia de la masa inconsciente; caemos 
en la debacle de una vida inauténticamente libre, en la pasividad, en la apatía y en la pereza para ejercer resistencia y crítica contra cualquier situación y determinación política que quebrante o viole nuestra plenitud de vida:

La conciencia de los problemas, en efecto, empuja hacía la evaluación de todos los anhelos y las tentativas de solución: fuente de mutuo respeto por la sinceridad común de la aspiración y del esfuerzo. (Mondolfo 1934, página 21)

Tener conciencia del valor superior que le corresponde a las exigencias del desarrollo propio es indispensable para que sean estas realizables. Esta adquisición de conciencia es un desarrollo de la personalidad de cada quien; la conquista de las condiciones exteriores está subordinada a la realización de las condiciones éticas y psicológicas; las condiciones exteriores, son su consecuencia. Si no existen las circunstancias interiores de la conciencia y la voluntad, resulta ineficaz e inservible que existan las circunstancias exteriores de la legislación y de la situación material. Resulta estéril que se le reconozca un derecho a quien no tenga la conciencia del mismo ni la voluntad para ejercitarlo: "El problema de renovación social, que constituye el programa de la democracia, es antes de todo y esencialmente un problema de renovación psicológica" (Mondolfo 1973, página 129-130). La libertad verdadera está determinada por ideales y valores que encontramos en la interioridad de nuestra conciencia; sin ellos, no se pueden esperar decisiones políticas respetuosas con los derechos humanos; y es que los derechos humanos también son valores:

(...) que se constituyen en 'fundamentales' respecto al ordenamiento jurídico, donde aparecen como supuestos axiomáticos que inspiran el sentido y las funciones que cada ordenamiento jurídico habría de asumir en forma de objetivos de política legislativa. (Sánchez de la Torre 2011, página 365)

Ahora bien, de los ideales y valores presentes en la interioridad de la conciencia depende la totalidad integral del desarrollo de los sujetos:

La libertad se obtiene solamente sumergiéndose en lo que es más íntimo a nuestra conciencia: más allá del intelecto, más allá de la razón priva por esto la conciencia, el asentimiento interior. La aspiración a la interioridad (...) es (...) esfuerzo hacia la libertad, no expresa, (...) de ninguna manera una tendencia individualista. (Mondolfo 1962, página 41-42)

\section{PERCEPCIONES FINALES}

Luego de lo expuesto, por un lado, sostendré que las decisiones políticas en derechos humanos deben tomarse principalmente con responsabilidad, pero esta responsabilidad debe tener como límite necesario a la convicción en los valores y derechos propios de la humanidad. Esto, por supuesto, implica también la necesidad de contar con un actuar serio y, sobre todo, sincero, activo y esmerado. Ser responsable en las determinaciones políticas y en los derechos humanos, no va de evitarse los problemas propios a costa de desatender nuestro deber, por ejemplo, de solidaridad para con los problemas "ajenos" que sufren los otros que consideremos que no pertenecen a nuestra comunidad. Pretender defender como una determinación política responsable la desatención a los derechos humanos, so pretexto de evitarnos problemas propios, es algo que resulta inaceptable $\mathrm{y}$ completamente irresponsable. Es aquí donde opera la ética de la convicción para saber cuándo estamos siendo realmente responsables o no con los derechos humanos.

Las convicciones se forjan con una buena educación en valores y derechos ciudadanos, de ahí que esta sea de especial relevancia en el desarrollo de nuestras sociedades. Un mundo sin una educación que impulse la capacidad de reflexión y de crítica de sus ciudadanos, sin una educación en valores, está condenado a convertirse en un mundo injusto, insolidario $\mathrm{y}$ desigual $\mathrm{y}$, con ello, en un mundo, a la larga, insostenible. Las convicciones de las determinaciones políticas deben tener en cuenta ello y estar forjadas, además, bajo la exigente conciencia de que todos pertenecemos a una misma unidad común, representada en la humanidad y en la dignidad de todos los seres humanos, sin excepción.

Por otro lado, también insistiré en afirmar que no existe una fuerza trascendental abstracta que guíe o determine a las decisiones políticas en uno u otro sentido o que guíe y determine la realidad en la que vivimos, como se podría interpretar de la parte de la filosofía de Hegel 
que hemos revisado aquí. En todo caso, si he de aceptar la existencia de una fuerza trascendental y determinante de la realidad y de nuestras decisiones, aceptaré entonces la idea de una fuerza trascendental determinante, pero concreta: sostengo que la concreción de esta fuerza se encarna en el ser humano. Somos los seres humanos lo concreto de esa fuerza que decide el destino de nuestras sociedades; somos los seres humanos los que ejercemos los cargos de representación política y, con ello, somos los que definimos y disponemos de las determinaciones políticas sobre la sociedad y sobre los derechos que la regulan. Estoy en desacuerdo con el filósofo Martín Heidegger (2005) y creo que se equivoca cuando niega la importancia de nuestra capacidad de pensar, afirmando que: "Lo que más merece pensarse en nuestro tiempo problemático es el hecho de que no pensamos"(página 17). Por el contrario, no puedo estar más de acuerdo con las acertadas afirmaciones del autor Ortega Gaisán (1958):

La inteligencia humana apunta (...) el primer hito para la grandeza humana. Tus pensamientos: eso eres tú. (...) Lo que cada hombre lleva en su cabeza, eso importa sobre todo y, antes que nada. (Página 273)

No hay sociedades, comunidades o pueblos sentenciados a sufrir por una determinante fuerza abstracta e invencible; somos los seres humanos los que, pensando y reflexionando, decidimos lo que sucede en nuestras sociedades; somos los llamados a ejercer nuestra fuerza concreta para interesarnos por los derechos de aquellos que son desatendidos, de aquellos desfavorecidos, o de aquellos que sufren el embiste de una guerra, del hambre o de la pobreza. La historia y la realidad no sobrevienen mecánica y automáticamente impuestas, sino que somos los seres humanos los que las decidimos: “(...) vivir es constantemente decidir lo que vamos a ser" (Ortega y Gasset 1984, página 195). z

Debo pues recalcar que en las decisiones políticas -y más para las referidas a la toma de decisiones sobre temas que se relacionen directa o indirectamente con los derechos humanos- se necesita contar con una conciencia y convicción sobre los valores superiores de nuestra humanidad. Esta conciencia y convicción nos exigirá ser responsables con nuestras decisiones y no nos permitirá ejercer un cargo, desatendiendo irresponsablemente nuestro comportamiento en relación a lo que el cargo me permita determinar en relación a las personas y sus derechos. Puede ser cierto que sea más fácil gobernar y decidir políticamente sin tener que atender problemas de pobreza, de desigualdad o de auxilio a quienes huyen del terror o de la guerra; no obstante, una mayor dificultad no puede eximir a nadie de asumir su responsabilidad humana de atención y solidaridad para con los demás. El problema "ajeno" tiene que ser tratado como un problema propioya que, en la realidad de nuestra humanidad, lo "ajeno" no existe. Hay que poner en práctica eso que he dado en llamar como la teoría de la empatía del reconocimiento. Con esta teoría planteo, que todos debemos saber reconocernos en todos, en todos los demás o, si se quiere, en los "otros", pues esos "otros" también somos nosotros. En la idea de unidad humana, todos somos parte de lo mismo y nos une un mismo interés de bienestar, dignidad y desarrollo. Si de esto se ve privado cualquier sujeto, más tarde o más temprano, en mayor o menor medida, nos terminará afectando a todos precisamente por esa idea de conjunto, vinculación y unidad, que es la que nos une ineludiblemente a todos por nuestra sola y propia condición de seres humanos.

Finalmente, dejo cerrado este trabajo afirmando que en las determinaciones políticas hay que reconocerse responsablemente en los requerimientos humanos de todos los pueblos, sin indiferencias ni justificaciones sesgadas que intenten justificar lo injustificable y que solo busquen excusar la desatención o la insuficiente atención a la eficiencia práctica y real de los derechos y, con ello, también de los derechos humanos. Debemos forjar sociedades que tengan unidad de sentimientos y unidad de deberes, con convicciones fundadas en los valores que nos hacen personas de bien. Como apunta el filósofo J. Cohn (1927, página 188): “(...) la unión de la voluntad más pura y del conocimiento de nuestras energías nativas y de la cohesión y relación histórica de ambas, esa es también nuestra misión."

\section{FUENTES DE INFORMACIÓN}

Abellán, Joaquín (2004). Poder y política en Max Weber. Madrid, España: Biblioteca Nueva.

Bourdieu, Pierre (2001). Poder, derecho y clases sociales. Traducido por $\mathrm{M}^{\mathrm{a}}$ José Bernuz Beneitez. Bilbao, España: Desclée, 
Cohn, Jonas (1927). Los grandes pensadores. Introducción histórica a la filosofía. Traducido por Domingo Miral. Barcelona, España: Labor.

Comte, Augusto (1985). Discurso sobre el espíritu positivo. Traducido por Consuelo Berges. Barcelona, España: Orbis.

D'hondt, Jacques (1971). Hegel, filósofo de la historia viviente. Traducido por Aníbal C. Leal. Buenos Aires, Argentina: Amorrortu.

Falcón y Tella, Fernando (2006). Nuevos retos de los derechos humanos. Madrid, España: Difusión Jurídica y Temas de Actualidad.

Hegel, Georg (1976). Filosofía de la historia. Traducido por Emanuel Suda. Buenos Aires, Argentina: Claridad,

Hegel, Georg (1968). Filosofía del derecho Traducido por Angélica Mendoza de Montero. Buenos Aires, Argentina: Claridad.

Heidegger, Martín (2005). ¿Qué significa pensar?. Traducido por Raúl Gabás. Madrid, España: Trotta.

Iturmendi Morales, José (1983). ed. "Una aproximación a los problemas del método jurídico desde la filosofía del derecho", en tomo I de Estudios de filosofía del derecho $y$ ciencia jurídica en memoria y homenaje al catedrático don Luis Legaz y Lacambra (1906-1980). Madrid: Centro de Estudios Constitucionales-Facultad de Derecho de la Universidad Complutense.

Mondolfo, Rodolfo (1961). "Significación del humanismo en el mundo contemporáneo". Revista de la Universidad de Buenos Aires 6 , quinta época, $\mathrm{n}^{\mathrm{o}} 3$.

Mondolfo, Rodolfo(1971) "Conclusiones sobre el marxismo". En Marx y Engels. Manifiesto comunista. Traducido por Alfonso Calderón. Santiago de Chile, Chile: Universitaria
Mondolfo, Rodolfo (1973). Entre la historia y la politica. Puebla, México: Cajica,

Mondolfo, Rodolfo (1943). "Roberto Ardigó y el Positivismo Italiano". Revista Sustancia, n ${ }^{\circ}$ 13.

Mondolfo, Rodolfo (1962). Rousseau y la conciencia moderna. Buenos Aires, Argentina: Eudeba,

Ortega y Gasset, José (1984). ¿Qué es filosofía? Madrid, España: Espasa-Calpe

Ortega Gaisan, Alejandro (1958). Valores humanos. Volumen III. Vitoria, España: Industria Gais

Peces-Barba, Gregorio (2005). "Dignidad humana", en 10 palabras clave sobre derechos humanos. Dirigido por Juan José Tamayo. Navarra, España: Verbo divino.

Sánchez de la Torre, Ángel (2011). "Noción 'formal' de los derechos humanos". Anuario de Derechos Humanos 12, Nueva época.

Vargas Jaramillo, Guillermo (2018). "Comentarios en torno a la idea de poder político en el 'ensayo sobre el gobierno civil' de John Locke". Revista peruana de ciencia política 2 .

Weber, Max (2007). El político y el científico. Traducido por Francisco Rubio Llorente. Madrid, España: Alianza.

Wences Simon, María (1998). En torno al origen del concepto moderno de sociedad civil (Locke, Ferguson y Hegel). Madrid, España: Dykinson. 